\title{
Optimization of the Thickness Ratio of Pd/Si Intermediate Layer in Co/Pd Multilayer Perpendicular Magnetic Recording Medium
}

\author{
J. Kawaji*, H. Hashimoto*, T. Asahi**, J. Hokkyo***, and T. Osaka*,**, *** \\ * Graduate School of Science \& Engineering, Waseda University, 3-4-1 Okubo, Shinjuku-ku, Tokyo 169-8555. \\ ** Graduate School of Science \& Engineering, Waseda University, 513 Waseda-tsurumaki-cho, Shinjuku-ku, Tokyo 162-0041. \\ *** Advanced Research Institute for Science \& Engineering, Waseda University, 3-4-1 Okubo, Shinjuku-ku, Tokyo 169-8555.
}

The effect of the thicknesses of Pd and Si films in the $\mathrm{Pd} / \mathrm{Si}$ dual intermediate layer on magnetic properties of the $\mathrm{Co} / \mathrm{Pd}$ multilayer for double-layered perpendicular magnetic recording medium was studied with the aim of developing an ultra-thin intermediate layer for producing fine magnetic clusters in the $\mathrm{Co} / \mathrm{Pd}$ multilayered film. The magnetic properties were found to be strongly dependent on the ratio of the Pd or Si layer thickness to the total thickness of the $\mathrm{Pd} / \mathrm{Si}$ dual film. When the ratio of the Pd layer thickness to the total thickness was $0.7-0.8$, high perpendicular coercivity and small slope parameter of the major hysteresis loop were attained simultaneously, which resulted from weak intergranular exchange coupling of the $\mathrm{Co} / \mathrm{Pd}$ multilayered film. In addition, the total thickness of the $\mathrm{Pd} / \mathrm{Si}$ intermediate layer was successfully reduced to $4 \mathrm{~nm}$, while retaining its high perpendicular coercivity and fine magnetic clusters, by optimizing the thicknesses of Pd and Si layers. Read-write experiments revealed that improvements in reproducing resolution and signal-to-noise ratio of the $\mathrm{Co} / \mathrm{Pd}$ multilayered media were achieved by the decrease in the intermediate layer thickness.

Key words: $\mathrm{Co} / \mathrm{Pd}$ multilayered film, perpendicular magnetic recording media, intermediate layer, $\mathrm{Pd} / \mathrm{Si}$ dual thin film, spacing loss, initial disordered layer

\section{Introduction}

A $\mathrm{Co} / \mathrm{Pd}$ multilayered film $\left([\mathrm{Co} / \mathrm{Pd}]_{\mathrm{n}}\right.$ film) exhibits high perpendicular magnetic anisotropy due to the surface anisotropy originating from the interface between Co and Pd sub-layers ${ }^{1)}$, and it has been attracting much attention as a recording layer of double-layered perpendicular magnetic recording media. One critical issue of the $[\mathrm{Co} / \mathrm{Pd}]_{\mathrm{n}}$ medium is formation of large magnetic clusters by strong intergranular exchange coupling of the $[\mathrm{Co} / \mathrm{Pd}]_{\mathrm{n}}$ film, which results in high medium noise. To decrease the magnetic cluster size, the introduction of a proper intermediate layer between the $[\mathrm{Co} / \mathrm{Pd}]_{\mathrm{n}}$ film and the soft magnetic underlayer (SUL) is as effective as the optimization of sputtering conditions ${ }^{2)-4)}$ and the addition of other elements to the $[\mathrm{Co} / \mathrm{Pd}]_{\mathrm{n}}$ film ${ }^{5)-7)}$. It has been reported that thin films of $\mathrm{Pd} / \mathrm{ITO}^{8)}, \mathrm{Pd}-\mathrm{SiN}^{9)}, \mathrm{Pd}-\mathrm{SiO}^{10}$, and $\mathrm{PtB} / \mathrm{Pd} / \mathrm{MgO}^{11)}$ are useful as an intermediate layer for $[\mathrm{Co} / \mathrm{Pd}]_{\mathrm{n}}$ media with fine magnetic clusters.

In our previous study, a $\mathrm{Pd}(5 \mathrm{~nm}) / \mathrm{Si}(5 \mathrm{~nm})$ dual thin film was developed as the seedlayer of $[\mathrm{Co} / \mathrm{Pd}]_{\mathrm{n}}$ single-layered media without SUL. Intergranular exchange coupling was substantially reduced when the $\mathrm{Pd} / \mathrm{Si}$ seedlayer was fabricated by combining the two preparation techniques: $\mathrm{N}_{2}$ addition to the sputtering gas and post-annealing of the deposited $\mathrm{Pd} / \mathrm{Si}$ layer ${ }^{12)}$. Additionally, the introduction of a $\mathrm{Pd}(5 \mathrm{~nm}) / \mathrm{Si}(5 \mathrm{~nm})$ film as an intermediate layer for the $[\mathrm{Co} / \mathrm{Pd}]_{\mathrm{n}}$ double-layered medium with CoZrNb SUL has also been found to be effective for reducing the intergranular exchange coupling ${ }^{13)}$. The $[\mathrm{Co} / \mathrm{Pd}]_{\mathrm{n}}$ double-layered media with a $\mathrm{Pd}(5 \mathrm{~nm}) / \mathrm{Si}(5 \mathrm{~nm})$ intermediate layer prepared by the combined process consisted of physically isolated, fine grains of $[\mathrm{Co} / \mathrm{Pd}]_{\mathrm{n}}$, which led to weak intergranular exchange coupling and the formation of fine magnetic clusters. Thus, the dual layer composed of $\mathrm{Pd}$ and $\mathrm{Si}$ films is a promising intermediate layer for improving the magnetic properties and read-write $(\mathrm{R} / \mathrm{W})$ performance of $[\mathrm{Co} / \mathrm{Pd}]_{\mathrm{n}}$ media. On the other hand, the lamination of $\mathrm{Pd}$ and $\mathrm{Si}$ sub-layers increases the total thickness of the dual intermediate layer, which is not desirable because of the spacing loss between the recording head and SUL or between the recording layer and SUL. Therefore, the dual intermediate layer should be as thin as possible.

In this study, to reduce the total thickness of the $\mathrm{Pd} / \mathrm{Si}$ intermediate layer without degrading magnetic properties, we optimized the thicknesses of Pd and Si layers. The effects of thicknesses of Pd and Si layers on the magnetic properties of $[\mathrm{Co} / \mathrm{Pd}]_{\mathrm{n}}$ film were investigated together with the effect of decreasing the intermediate layer thickness on the $\mathrm{R} / \mathrm{W}$ performance of the medium.

\section{Experimental details}

Thin film media composed of [Co $(0.2 \mathrm{~nm}) / \mathrm{Pd}(0.8$ $\mathrm{nm})]_{\mathrm{n}} / \mathrm{Pd}(\mathrm{x} \mathrm{nm}) / \mathrm{Si}(\mathrm{y} \mathrm{nm}) / \mathrm{Co}_{91} \mathrm{Zr}_{5} \mathrm{Nb}_{4}(300 \mathrm{~nm}) /$ glass substrate were prepared by using a dc magnetron sputtering system, where $\mathrm{n}$ was the number of layers ranging from 5 to 20 , and $\mathrm{x}$ and $\mathrm{y}$ were varied from 0 to 10 . The Pd and Si sub-layers in the intermediate layer are designated as "Pd upper-intermediate layer" and "Si under-intermediate layer", respectively. The CoZrNb SUL showed an isotropic magnetic property, and the saturation magnetic flux density and in-plane coercivity were $1.4 \mathrm{~T}$ and $10 \mathrm{Oe}$, respectively. After the CoZrNb film was deposited on a glass substrate at room temperature, the sample was taken out of the sputtering 
chamber and exposed to air atmosphere. Then the sample was reloaded into the sputtering chamber, and a $\mathrm{Pd} / \mathrm{Si}$ intermediate layer and a $[\mathrm{Co} / \mathrm{Pd}]_{\mathrm{n}}$ film were successively deposited without any etching treatment of the SUL surface. The Ar sputtering gas pressure was set at 5, 20, and $100 \mathrm{mT}$ orr for the $\mathrm{CoZrNb},[\mathrm{Co} / \mathrm{Pd}]_{\mathrm{n}}$, and $\mathrm{Pd} / \mathrm{Si}$ films, respectively. The $\mathrm{Si}$ under-intermediate layer was deposited in pure Ar gas, whereas the Pd upper-intermediate layer was deposited in an $\mathrm{Ar}$ gas atmosphere containing $\mathrm{N}_{2}$ at 5 mTorr. After the deposition of $\mathrm{Pd} / \mathrm{Si}$ layer, the sample was post-annealed at $400{ }^{\circ} \mathrm{C}$ for 50 minutes, and then it was allowed to cool down slowly in the sputtering chamber. Finally, $[\mathrm{Co} / \mathrm{Pd}]_{\mathrm{n}}$ films were deposited at room temperature. The $5 \mathrm{~nm}$ carbon overcoat layer was deposited on the $[\mathrm{Co} / \mathrm{Pd}]_{\mathrm{n}}$ film at an $\mathrm{Ar}$ gas pressure of $50 \mathrm{mT}$ Torr for the media used in $\mathrm{R} / \mathrm{W}$ experiments.

Magnetic properties were evaluated by using a polar Kerr magnetometer with the maximum applied magnetic field of $15 \mathrm{kOe}$. Magnetization states of $[\mathrm{Co} / \mathrm{Pd}]_{\mathrm{n}}$ media were observed by using a magnetic force microscope (MFM). Magnetic domain size was calculated as the average diameter of virtual circles with the same area as the magnetic domains in MFM images at the ac-demagnetized state. The $\mathrm{R} / \mathrm{W}$ performance was estimated by a merged type giant magneto resistive (GMR) head under the conditions shown in Table 1, which also shows head specifications. The state of chemical bonding of the $\mathrm{Pd} / \mathrm{Si}$ film surface was investigated by using x-ray photoelectron spectroscopy (XPS) with an $\mathrm{Al}-\mathrm{K}_{\alpha}$ radiation (acceleration voltage: $10 \mathrm{kV}$, emission current: $10 \mathrm{~mA}$ ). To obtain information on the chemical bonding in the vicinity of only the uppermost layer of $\mathrm{Pd} / \mathrm{Si}$ film, total reflection XPS ${ }^{14)}$ was used. In the total reflection XPS, an X-ray was irradiated onto the film surface with an incident angle less than the critical angle to prevent the x-ray from penetrating into the film. For comparison, XPS with an incident angle of $c a .10$ deg was also performed, which is designated as "conventional
XPS" in this paper. From the result of a preliminary experiment, the penetration depth of $\mathrm{X}$-ray was estimated to be greater than $10 \mathrm{~nm}$ in the conventional XPS.

Table 1 Conditions of read-write experiment.

\begin{tabular}{lll}
\hline \hline Write head & Gap length & $0.15 \mu \mathrm{m}$ \\
& Track width & $0.38 \mu \mathrm{m}$ \\
\hline Read head & Gap length & $0.09 \mu \mathrm{m}$ \\
& Track width & $0.24 \mu \mathrm{m}$ \\
\hline Flying height & $12 \mathrm{~nm}$ \\
\hline Liner velocity & $6.35 \mathrm{~m} / \mathrm{s}$ \\
\hline \hline
\end{tabular}

\section{Results}

\subsection{Magnetic properties}

The dependencies of perpendicular coercivity $\left(H_{\mathrm{c}}\right)$ and $\alpha$ value of the $[\mathrm{Co} / \mathrm{Pd}]_{20}$ films on the thicknesses of $\mathrm{Pd}$ upper- and $\mathrm{Si}$ under-intermediate layers (denoted as $\delta_{\mathrm{Pd}}$ and $\delta_{\mathrm{Si}}$, respectively) are shown in Figs.1 (a) and 1 (b), for which the total thicknesses of $\mathrm{Pd} / \mathrm{Si}$ intermediate layers $\left(\delta_{\mathrm{Pd} / \mathrm{Si}}\right)$ were $10 \mathrm{~nm}$ and $5 \mathrm{~nm}$, respectively. The $\alpha$ value of $[\mathrm{Co} / \mathrm{Pd}]_{\mathrm{n}}$ film is the parameter reflecting the strength of intergranular exchange coupling of $[\mathrm{Co} / \mathrm{Pd}]_{\mathrm{n}}$ film ${ }^{15),}{ }^{16)}$, and it is defined as follows:

$$
\alpha=4 \pi\left(\mathrm{d} \theta_{\mathrm{k}} / \mathrm{d} H\right)_{H=H \mathrm{c}} \times\left(M_{\mathrm{s}} / \theta_{\mathrm{kmax}}\right) \text {, }
$$

where $\left(\mathrm{d} \theta_{\mathrm{k}} / \mathrm{d} H\right)_{\mathrm{H}=\mathrm{Hc}}$ and $\theta_{\mathrm{kmax}}$ are the derivative at the coercivity and the maximum rotation angle of a Kerr hysteresis loop, respectively. In this study, the saturation magnetization $\left(M_{\mathrm{s}}\right)$ of all media was assumed to be equal to $320 \mathrm{emu} / \mathrm{cm}^{3}$, which is the value for the single-layered medium composed of $[\mathrm{Co} / \mathrm{Pd}]_{20} / \mathrm{Pd}(5 \mathrm{~nm}) / \mathrm{Si}(5 \mathrm{~nm}) /$ glass substrate ${ }^{12)}$. When $\delta_{\mathrm{Pd} / \mathrm{Si}}$ was fixed at $10 \mathrm{~nm}$, the values of $H_{\mathrm{c}}$ and $\alpha$ were greatly dependent on $\delta_{\mathrm{Pd}}$ and $\delta_{\mathrm{Si}}$. The value of $H_{\mathrm{c}}$ exhibited a maximum at $\left(\delta_{\mathrm{Pd}}, \delta_{\mathrm{Si}}\right)=(7 \mathrm{~nm}$, $3 \mathrm{~nm}$ ), while the $\alpha$ value was at its minimum at the same values of $\delta_{\mathrm{Pd}}$ and $\delta_{\mathrm{Si}}$. Conceivably, the increase in $H_{\mathrm{c}}$

\section{(b) Thickness of Si layer [nm]}

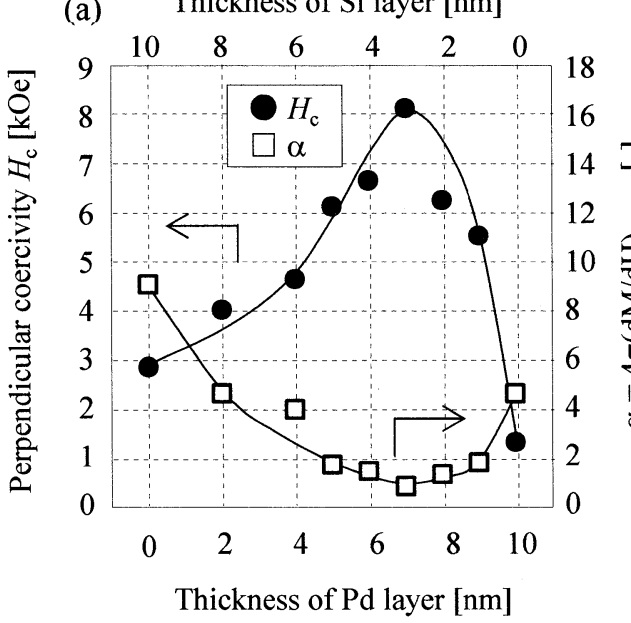

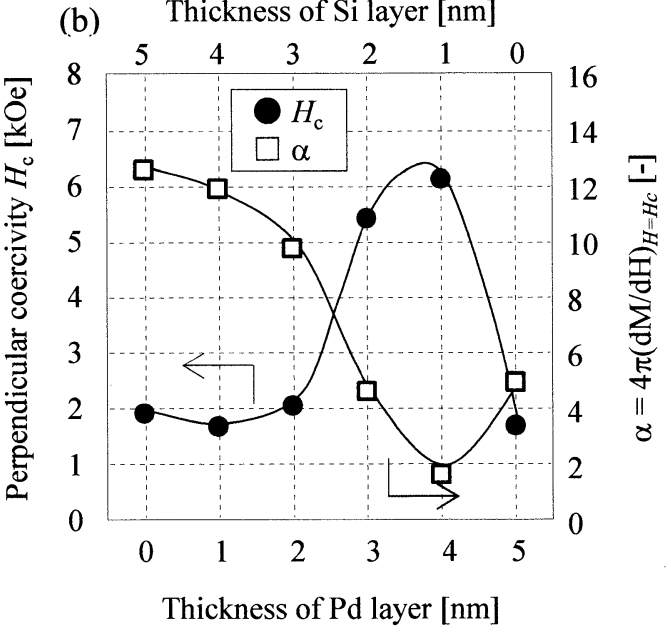

Fig.1 Dependence of $H_{\mathrm{c}}$ and $\alpha$ of $[\mathrm{Co} / \mathrm{Pd}]_{20}$ media on the thicknesses of Pd upper- or Si under-intermediate layers, where the total thickness of the $\mathrm{Pd} / \mathrm{Si}$ intermediate layer was $10 \mathrm{~nm}$ (a) and $5 \mathrm{~nm}(\mathrm{~b})$, respectively. 

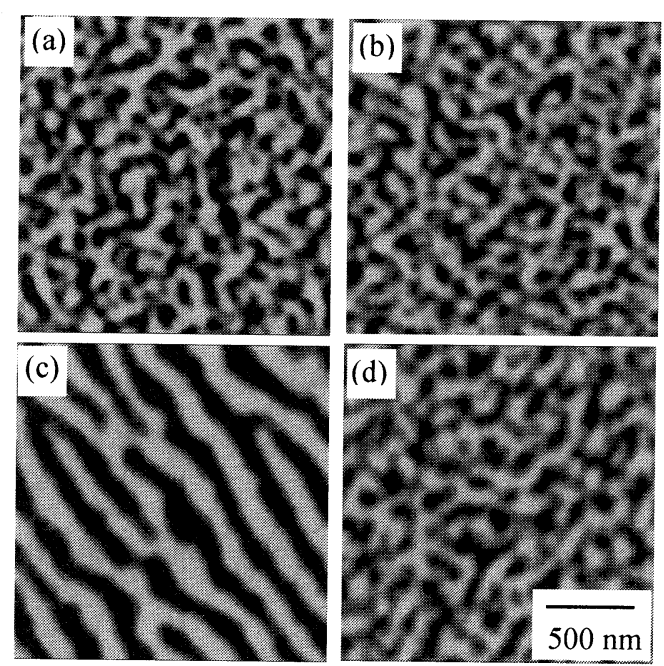

Fig.2 MFM images at ac-demagnetized state of $[\mathrm{Co} / \mathrm{Pd}]_{20}$ media with intermediate layers composed of $\mathrm{Pd}(4 \mathrm{~nm}) / \mathrm{Si}(1 \mathrm{~nm})(\mathrm{a})$, $\operatorname{Pd}(3 \mathrm{~nm}) / \mathrm{Si}(0.75 \mathrm{~nm})(\mathrm{b}), \quad \operatorname{Pd}(2 \mathrm{~nm}) / \mathrm{Si}$ $(0.5 \mathrm{~nm})(\mathrm{c})$, and $\operatorname{Pd}(5 \mathrm{~nm}) / \mathrm{Si}(5 \mathrm{~nm})(\mathrm{d})$, respectively.

was due to a change in magnetization reversal mode from wall displacement to rotation magnetization ${ }^{17)}$, which apparently resulted from the reduction in intergranular exchange coupling of the $[\mathrm{Co} / \mathrm{Pd}]_{20}$ medium $^{18)}$. This interpretation agrees with the result of measurement of $\alpha$ values. When $\delta_{\mathrm{Pd} / \mathrm{Si}}$ was $5 \mathrm{~nm}$, the dependencies of $H_{\mathrm{c}}$ and $\alpha$ on $\delta_{\mathrm{Pd}}$ and $\delta_{\mathrm{Si}}$ were similar to those observed when $\delta_{\mathrm{Pd} / \mathrm{Si}}=10 \mathrm{~nm}$. It is seen in both Figs. 1 (a) and 1(b) that the highest $H_{\mathrm{c}}$ and lowest $\alpha$ were attained simultaneously, when the ratio of $\delta_{\mathrm{Pd}}$ to $\delta_{\mathrm{Pd} / \mathrm{Si}}\left(\delta_{\mathrm{Pd}} / \delta_{\mathrm{Pd} / \mathrm{Si}}\right)$ was $0.7-0.8$ (namely, $\delta_{\mathrm{Si}} / \delta_{\mathrm{Pd} / \mathrm{Si}}$ was $0.2-0.3$ ). These results suggest that magnetic properties of the $[\mathrm{Co} / \mathrm{Pd}]_{20}$ medium with $\mathrm{Pd} / \mathrm{Si}$ intermediate layer strongly depend on the thickness ratio, $\delta_{\mathrm{Pd}} / \delta_{\mathrm{Pd} / \mathrm{Si}}$ or $\delta_{\mathrm{Si}} / \delta_{\mathrm{Pd} / \mathrm{Si}}$, and that intergranular exchange coupling of the medium is reduced significantly by using the $\mathrm{Pd} / \mathrm{Si}$ intermediate layer with the characteristic thickness ratio of $\left(\delta_{\mathrm{Pd}} / \delta_{\mathrm{Pd} / \mathrm{Si}}, \delta_{\mathrm{Si}} / \delta_{\mathrm{Pd} / \mathrm{Si}}\right)=(0.7-0.8,0.2-0.3)$. Based on these results, we attempted to reduce total thickness of $\mathrm{Pd} / \mathrm{Si}$ intermediate layer with the thickness ratio fixed at $\left(\delta_{\mathrm{Pd}} / \delta_{\mathrm{Pd} / \mathrm{Si}}, \delta_{\mathrm{Si}} / \delta_{\mathrm{Pd} / \mathrm{Si}}\right)=(0.8,0.2)$.

Figures 2 (a)-(c) show MFM images at the

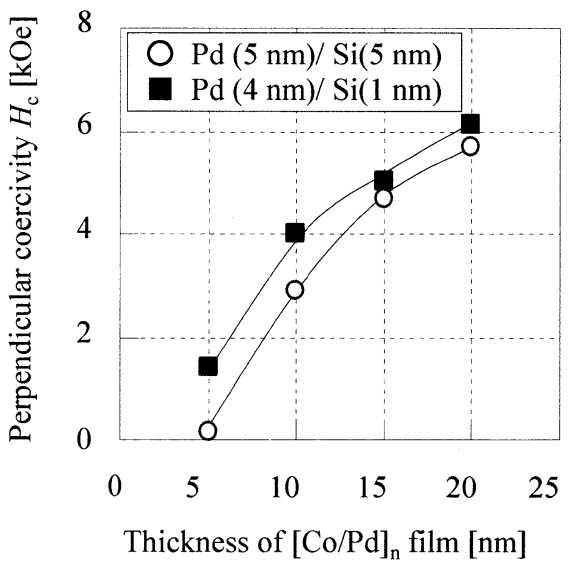

Fig.3 Dependence of perpendicular coercivity of $[\mathrm{Co} / \mathrm{Pd}]_{\mathrm{n}}$ media on the thickness of $[\mathrm{Co} / \mathrm{Pd}]_{\mathrm{n}}$ film, where a $\mathrm{Pd} / \mathrm{Si}$ intermediate layer consisted of $\operatorname{Pd}(5 \mathrm{~nm}) / \mathrm{Si}(5 \mathrm{~nm})$ or $\mathrm{Pd}(4$ $\mathrm{nm}) / \mathrm{Si}(1 \mathrm{~nm})$.

ac-demagnetized state of $[\mathrm{Co} / \mathrm{Pd}]_{20}$ media with a $\mathrm{Pd} / \mathrm{Si}$ layer at $\left(\delta_{\mathrm{Pd}} / \delta_{\mathrm{Pd} / \mathrm{Si}}, \quad \delta_{\mathrm{Si}} / \delta_{\mathrm{Pd} / \mathrm{Si}}\right)=(0.8, \quad 0.2)$. Magnetic properties and magnetic cluster sizes of the $[\mathrm{Co} / \mathrm{Pd}]_{20}$ media are tabulated in Table 2 . For comparison, the results obtained with the $[\mathrm{Co} / \mathrm{Pd}]_{20}$ medium with a $\mathrm{Pd}(5$ $\mathrm{nm}) / \mathrm{Si}(5 \mathrm{~nm})$ layer are also shown in Fig. $2(\mathrm{~d})$ and Table 2. The $[\mathrm{Co} / \mathrm{Pd}]_{20}$ medium with a $\mathrm{Pd}(4 \mathrm{~nm}) / \mathrm{Si}(1 \mathrm{~nm})$ or a $\mathrm{Pd}(3 \mathrm{~nm}) / \mathrm{Si}(0.75 \mathrm{~nm})$ layer, as well as the medium with a $\mathrm{Pd}(5 \mathrm{~nm}) / \mathrm{Si}(5 \mathrm{~nm})$ layer, exhibited a high $H_{\mathrm{c}}$, a small $\alpha$, and a small size of magnetic clusters. However, the medium with a $\mathrm{Pd}(2 \mathrm{~nm}) / \mathrm{Si}(0.5 \mathrm{~nm})$ layer showed a small $H_{\mathrm{c}}$, a high $\alpha$, and a stripe maze pattern, revealing that the $\mathrm{Pd}(2 \mathrm{~nm}) / \mathrm{Si}(0.5 \mathrm{~nm})$ intermediate layer was not effective to reduce the intergranular exchange coupling of $[\mathrm{Co} / \mathrm{Pd}]_{\mathrm{n}}$ film. Clearly, the optimization of the $\mathrm{Pd} / \mathrm{Si}$ thickness ratio made it possible for the $\mathrm{Pd} / \mathrm{Si}$ thickness to be decreased to approximately $4 \mathrm{~nm}$ without any deterioration of magnetic properties.

Figure 3 shows the dependence of $H_{\mathrm{c}}$ value on the thickness of $[\mathrm{Co} / \mathrm{Pd}]_{\mathrm{n}}$ film for the medium with a $\mathrm{Pd}(5$ $\mathrm{nm}) / \mathrm{Si}(5 \mathrm{~nm})$ or a $\mathrm{Pd}(4 \mathrm{~nm}) / \mathrm{Si}(1 \mathrm{~nm})$ layer. The value

Table 2 Perpendicular coercivity, $\alpha$ value, and magnetic cluster size of $[\mathrm{Co} / \mathrm{Pd}]_{\mathrm{n}}$ media containing a $\mathrm{Pd} / \mathrm{Si}$ intermediate layer with various thickness ratios.

\begin{tabular}{ccccccc}
\hline \hline $\begin{array}{c}\text { Thickness ratio of } \\
\mathrm{Pd} / \mathrm{Si} \text { intermediate layer } \\
\left(\delta_{\mathrm{Pd}} / \delta_{\mathrm{Pd} / \mathrm{Si}}, \delta_{\mathrm{Si}} / \delta_{\mathrm{Pd} / \mathrm{Si}}\right)\end{array}$ & $\delta_{\mathrm{Pd}}[\mathrm{nm}]$ & $\delta_{\mathrm{Si}}[\mathrm{nm}]$ & $\delta_{\mathrm{Pd} / \mathrm{Si}}[\mathrm{nm}]$ & $H_{\mathrm{c}}[\mathrm{kOe}]$ & $\alpha$ value [-] & $\begin{array}{c}\text { Magnetic cluster } \\
\text { size } \\
{[\mathrm{nm}]}\end{array}$ \\
\hline & 4 & 1 & 5 & 6.1 & 1.9 & $106 \pm 22$ \\
$(0.8,0.2)$ & 3 & 0.75 & 3.75 & 6.1 & 1.9 & $110 \pm 19$ \\
& 2 & 0.5 & 2.5 & 2.4 & 6.1 & (not determined) \\
\hline \hline
\end{tabular}


of $H_{\mathrm{c}}$ decreased with decreasing $\delta_{\mathrm{Co} / \mathrm{Pd}}$ in both cases, which is likely to be due to a thermal fluctuation caused by the reduction of magnetic grain volume and to the influence of an initial disordered layer in the $[\mathrm{Co} / \mathrm{Pd}]_{\mathrm{n}}$ film. The $[\mathrm{Co} / \mathrm{Pd}]_{\mathrm{n}}$ medium with $\mathrm{Pd}(4 \mathrm{~nm}) / \mathrm{Si}(1 \mathrm{~nm})$ showed a higher $H_{\mathrm{c}}$ value than that with $\operatorname{Pd}(5 \mathrm{~nm}) / \operatorname{Si}(5 \mathrm{~nm})$, and the difference in $H_{\mathrm{c}}$ between the two media became larger with decreasing thickness of the $[\mathrm{Co} / \mathrm{Pd}]_{\mathrm{n}}$ layer. This result implies that the formation of initial disordered layer was suppressed in the medium with $\operatorname{Pd}(4 \mathrm{~nm}) / \mathrm{Si}(1 \mathrm{~nm})$ in comparison with that with $\operatorname{Pd}(5 \mathrm{~nm}) / \operatorname{Si}(5 \mathrm{~nm})$, which is desirable for improving the $\mathrm{R} / \mathrm{W}$ performance.

\subsection{Effect of the intermediate layer thickness on} read-write performance

As shown in Table 2 , the $[\mathrm{Co} / \mathrm{Pd}]_{20}$ media with $\mathrm{Pd}(5$ $\mathrm{nm}) / \mathrm{Si}(5 \mathrm{~nm})$ and with $\mathrm{Pd}(4 \mathrm{~nm}) / \mathrm{Si}(1 \mathrm{~nm})$, designated respectively as "medium I" and "medium II", exhibit similar magnetic properties. Therefore, the effect of reduction of the intermediate layer thickness $\left(\delta_{\mathrm{Pd} / \mathrm{Si}}\right)$ on $\mathrm{R} / \mathrm{W}$ performance can be reasonably evaluated by comparing $\mathrm{R} / \mathrm{W}$ performances of the two media. Figure 4 shows the dependence of normalized outputs of media I and II on recording current. When the recording current was smaller than $10 \mathrm{~mA}$, the reproduced voltage of medium II increased more sharply with increasing recording current than that of medium $\mathrm{I}$. The recording sensitivity was improved clearly by reducing $\delta_{\mathrm{Pd} / \mathrm{Si}}$ from 10 $\mathrm{nm}$ to $5 \mathrm{~nm}$. Table 3 shows values of reproducing voltage at $25 \mathrm{kFRPI}, \mathrm{D}_{50}$, and signal-to-noise ratio (S/N ratio) at $300 \mathrm{kFRPI}$ of media I and II. The value of $\mathrm{D}_{50}$ is

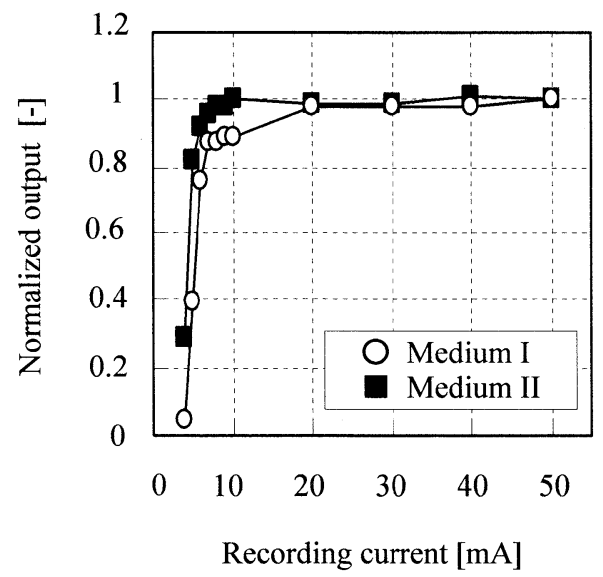

Fig.4 Dependence of normalized output of media I and II on recording current at $300 \mathrm{kFRPI}$. defined as the linear recording density where the reproducing voltage is equal to one half of that at 25 kFRPI. The reproducing voltage at low recording densities was increased and the reproducing resolution was improved by reducing $\delta_{\mathrm{Pd} / \mathrm{Si}}$. Decreasing the intermediate layer thickness resulted in the decrease in the distance between the recording head and SUL, causing the magnetic recorded bits to be easily reversed by the perpendicular magnetic flux from the recording head to SUL. Additionally, the decrease in the distance between the recording layer and SUL is expected to enhance the "mirror effect" of the SUL in the reproducing process ${ }^{19}$ ). These effects are likely to improve the reproduced voltage and the reproducing resolution. On the other hand, there was no significant difference between media I and II in the medium noise normalized by the reproducing voltage at 25 kFRPI. Therefore, the slight increase in $\mathrm{S} / \mathrm{N}$ ratio observed with the reduction of $\delta_{\mathrm{Pd} / \mathrm{Si}}$ shown in Table 3 is mainly attributable to the improvement of reproducing resolution.

\section{Discussion}

The thickness ratio of the $\mathrm{Pd} / \mathrm{Si}$ intermediate layer strongly affects magnetic properties of the $[\mathrm{Co} / \mathrm{Pd}]_{\mathrm{n}}$ film, which is related to the initial grain growth. In this section, the correlation between magnetic properties of the $[\mathrm{Co} / \mathrm{Pd}]_{\mathrm{n}}$ film and the thickness ratio of $\mathrm{Pd} / \mathrm{Si}$ in the intermediate layer is discussed, based on the microstructure of $\operatorname{Pd}(5 \mathrm{~nm}) / \operatorname{Si}(5 \mathrm{~nm})$ intermediate layer.

4.1 Microstructure of $\operatorname{Pd}(5 \mathrm{~nm}) / \operatorname{Si}(5 \mathrm{~nm})$ intermediate layer $^{13)}$

As described in our previous reports ${ }^{12)}{ }^{13)}$, the $\mathrm{Pd} / \mathrm{Si}$ intermediate layer prepared by combining $\mathrm{N}_{2}$ addition to the sputtering gas and post-annealing effectively suppressed the intergranular exchange coupling. Our TEM observation of $[\mathrm{Co} / \mathrm{Pd}]_{20}$ media with a $\mathrm{Pd}(5 \mathrm{~nm}) / \mathrm{Si}(5$ $\mathrm{nm}$ ) intermediate layer revealed that the addition of $\mathrm{N}_{2}$ gas decreased the grain size of Pd upper-intermediate layer ${ }^{13}$. On the other hand, the post-annealing process enhanced the diffusion of $\mathrm{Si}$ into the Pd upper-intermediate layer. This Si diffusion was clearly observed by XPS analysis. Figures 5 (a) and 5 (b) show conventional and total reflection $\mathrm{x}$-ray photoelectron $(\mathrm{XP})$ spectra at $\mathrm{Si}-2 \mathrm{p}$ region of the $\mathrm{Pd} / \mathrm{Si} / \mathrm{CoZrNb}$ films designated as films $\mathrm{A}, \mathrm{B}$, and C. The preparation conditions, the compositions of films $\mathrm{A}-\mathrm{C}$ and the magnetic properties of $[\mathrm{Co} / \mathrm{Pd}]_{20}$ films deposited on them are summarized in Table 4 . For film $\mathrm{A}$, the XP signal from Si-compound, mainly $\mathrm{Si}-\mathrm{O}$, was observed in curve (i) of Fig.5 (a). However, the signal

Table 3 Reproducing voltage at $25 \mathrm{kFRPI}, \mathrm{D}_{50}$ value, and $\mathrm{S} / \mathrm{N}$ ratio at $300 \mathrm{kFRPI}$ of $[\mathrm{Co} / \mathrm{Pd}]_{20}$ media with a $\mathrm{Pd}(5 \mathrm{~nm}) / \mathrm{Si}(5 \mathrm{~nm})$ intermediate layer (medium I) and a $\mathrm{Pd}(4 \mathrm{~nm}) / \mathrm{Si}(1 \mathrm{~nm})$ intermediate layer (medium II).

\begin{tabular}{ccccc}
\hline \hline Medium & Intermediate layer & $\begin{array}{c}\text { Reproducing voltage } \\
\text { at 25 kFRPI }\left[\mathrm{mV}_{\mathrm{p}-\mathrm{p}}\right]\end{array}$ & $\begin{array}{c}\mathrm{D}_{50} \\
{[\mathrm{kFRPI}]}\end{array}$ & $\begin{array}{c}\text { S/N ratio at 300 kFRPI } \\
{\left[\mathrm{dB}_{\mathrm{p}-\mathrm{p} / \mathrm{rms}}\right]}\end{array}$ \\
\hline $\mathrm{I}$ & $\mathrm{Pd}(5 \mathrm{~nm}) / \mathrm{Si}(5 \mathrm{~nm})$ & 540 & 250 & 11.6 \\
$\mathrm{II}$ & $\mathrm{Pd}(4 \mathrm{~nm}) / \mathrm{Si}(1 \mathrm{~nm})$ & 590 & 265 & 12.4 \\
\hline \hline
\end{tabular}


was not detected under the total reflection condition as shown in curve (i') of Fig.5 (b). In contrast, for film B, the peak originating from $\mathrm{Si}-\mathrm{O}$ was seen even in the total reflection XP spectrum ((ii') of Fig.5 (b)), indicating that

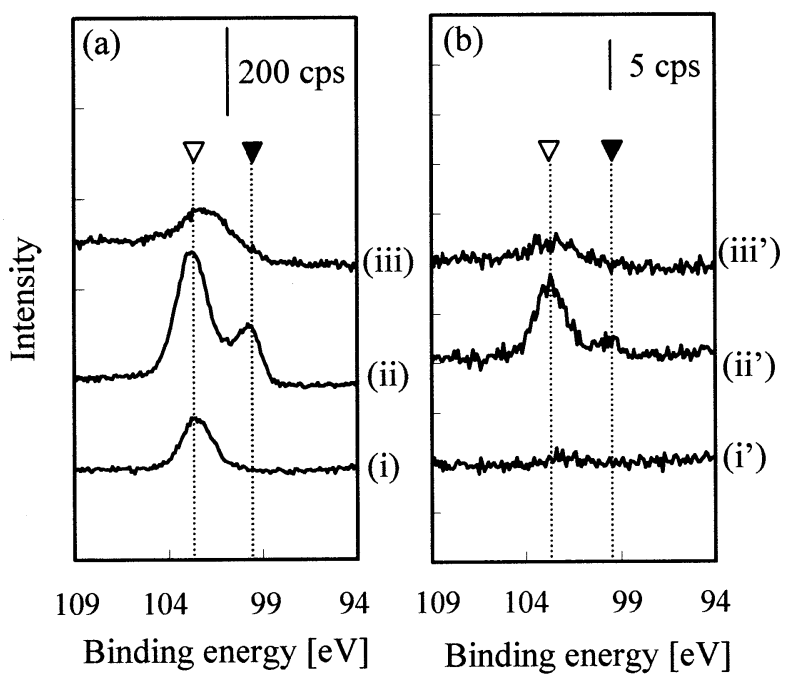

Fig.5 Si-2p x-ray photoelectron spectra of $\mathrm{Pd} / \mathrm{Si}$ film deposited on $\mathrm{CoZrNb}$ layers recorded in the conventional (a) and total reflection (b) mode. Spectra labeled (i, i'), (ii, ii'), and (iii, iii') were obtained with films $\mathrm{A}, \mathrm{B}$, and $\mathrm{C}$, respectively. Binding energies of $\mathrm{Si}-\mathrm{O}$ (open triangle) and metal silicide (solid triangle) are indicated by dotted lines.

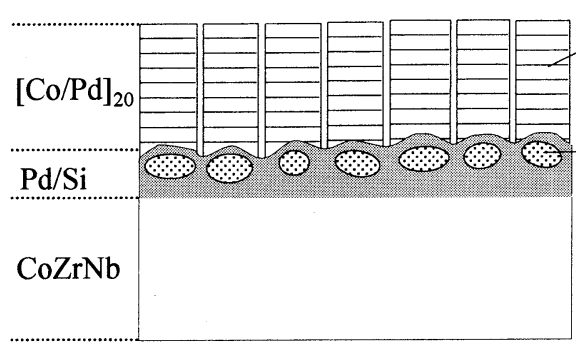

Physically isolated $[\mathrm{Co} / \mathrm{Pd}]_{\mathrm{n}}$ grains Pd grains surrounded by Si matrices

Fig.6 Schematic representation of the structure of $[\mathrm{Co} / \mathrm{Pd}]_{\mathrm{n}}$ media with $\mathrm{Pd}(5 \mathrm{~nm}) / \mathrm{Si}(5 \mathrm{~nm})$ intermediate layer prepared with $\mathrm{N}_{2}$ addition and post-annealing.
Si-compound existed in the uppermost layer of the $\mathrm{Pd} / \mathrm{Si}$ film. These results suggest that the post-annealing enhanced the diffusion of $\mathrm{Si}$ in the intermediate layer. Furthermore, no signal from metal silicides was observed in film $\mathrm{A}$, whereas it was observed in film $\mathrm{B}$, which indicates that formation of alloys of $\mathrm{Pd}$ and $\mathrm{Si}$ such as $\mathrm{Pd}_{2} \mathrm{Si}$ was also promoted by the post-annealing process ${ }^{12)}$.

Based on the above discussions, a schematic model for a $[\mathrm{Co} / \mathrm{Pd}]_{\mathrm{n}}$ medium with a Pd $(5 \mathrm{~nm}) / \mathrm{Si}(5 \mathrm{~nm})$ intermediate layer fabricated with $\mathrm{N}_{2}$ addition and post-annealing was prepared, and it is shown in Fig.6. In TEM observation ${ }^{13}$, $\mathrm{Si}$ was found not only to diffuse to grain boundaries of the $\mathrm{Pd}$ layer but also to penetrate readily through the $\mathrm{Pd}$ layer to the top surface of the intermediate layer. Consequently, the $\mathrm{Pd} / \mathrm{Si}$ intermediate layer exhibited a granular structure with $\mathrm{Si}$-compound matrices surrounding fine $\mathrm{Pd}$ grains, which provided suitable nucleation sites for physically isolated $[\mathrm{Co} / \mathrm{Pd}]_{\mathrm{n}}$ grains, resulting in a decrease in intergranular exchange coupling.

4.2 Correlation between the thickness ratio of $\mathrm{Pd} / \mathrm{Si}$ in the intermediate layer and magnetic properties of $[\mathrm{Co} / \mathrm{Pd}]_{\mathbf{n}}$ film

In the $\mathrm{Pd} / \mathrm{Si}$ intermediate layer prepared with $\mathrm{N}_{2}$ addition and post-annealing, Si plays a significant role in the form of Si-compound matrices surrounding fine $\mathrm{Pd}$ grains. However, the presence of an excessive amount of diffused $\mathrm{Si}$ on the top surface of the $\mathrm{Pd} / \mathrm{Si}$ intermediate layer seems to cause the formation of an initial disordered layer, as it has been reported that an initial disordered layer is formed at the interface between the multilayer and the underlayer in the $[\mathrm{Co} / \mathrm{Pd}]_{\mathrm{n}}$ single-layered media with a Si $(100 \mathrm{~nm})$ underlayer ${ }^{20), 21)}$. Figure 3 suggests that the perpendicular coercivity of a $[\mathrm{Co} / \mathrm{Pd}]_{\mathrm{n}}$ film on $\mathrm{Pd}(5$ $\mathrm{nm}) / \mathrm{Si}(5 \mathrm{~nm})$ intermediate layer is strongly affected by the initial disordered region compared with that on a Pd (4 $\mathrm{nm}) / \mathrm{Si}(1 \mathrm{~nm})$ layer. Therefore, the change in film composition of the $\mathrm{Pd} / \mathrm{Si}$ layer is considered to affect the degree of Si diffusion in the intermediate layer. Here, we will estimate the degree of $\mathrm{Si}$ diffusion into the $\mathrm{Pd}$ upper-intermediate layer from the integrated intensity of the XP signal from Si. Figure 7 compares the normalized integrated peak intensities from Si compounds for films A, $\mathrm{B}$, and C. The integrated intensity from Si-2p peak (Fig. 5) was normalized by that from Pd-3d peak shown in Fig. 8. As Si diffuses excessively through the Pd layer, the

Table 4 Film composition and preparation conditions of $\mathrm{Pd} / \mathrm{Si} / \mathrm{CoZrNb}$ thin films used in XPS measurement. Magnetic proprieties of $[\mathrm{Co} / \mathrm{Pd}]_{20}$ films deposited on $\mathrm{Pd} / \mathrm{Si} / \mathrm{CoZrNb}$ films are also shown.

\begin{tabular}{cccccc}
\hline \hline Film & Film compositon & \multicolumn{2}{c}{ Preparation conditions } & \multicolumn{2}{c}{$\begin{array}{c}\text { Magnetic properties of [Co/Pd }]_{20} \\
\text { film deposited on the films }\end{array}$} \\
\cline { 3 - 6 } & & $\mathrm{N}_{2}$ addition & Post-annealing & $H_{\mathrm{c}}[\mathrm{kOe}]$ & $\alpha[-]$ \\
\hline $\mathrm{A}$ & $\mathrm{Pd}(5 \mathrm{~nm}) / \mathrm{Si}(5 \mathrm{~nm})$ & $\bigcirc$ & $\times$ & 4.7 & 6.2 \\
$\mathrm{~B}$ & $\mathrm{Pd}(5 \mathrm{~nm}) / \mathrm{Si}(5 \mathrm{~nm})$ & $\bigcirc$ & $\bigcirc$ & 5.7 & 1.9 \\
$\mathrm{C}$ & $\mathrm{Pd}(4 \mathrm{~nm}) / \mathrm{Si}(1 \mathrm{~nm})$ & $\bigcirc$ & $\bigcirc$ & 6.0 & 1.9 \\
\hline \hline
\end{tabular}




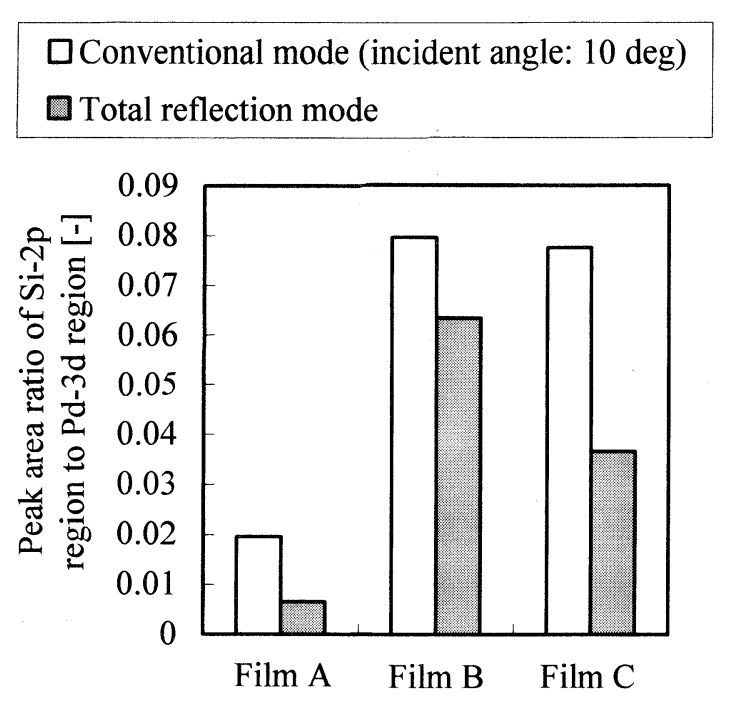

Fig.7 XPS integrated peak intensity ratios of $\mathrm{Si}-2 \mathrm{p}$ to that of Pd-3d obtained in the conventional mode (white), and in the total reflection mode (gray) for films A, B, and $\mathrm{C}$.

normalized integrated peak intensity becomes relatively large. Thus, it is possible to evaluate the difference in the degree of excessive diffusion of $\mathrm{Si}$ between the medium with $\mathrm{Pd}(5 \mathrm{~nm}) / \mathrm{Si}(5 \mathrm{~nm})$ and that with $\mathrm{Pd}(4$ $\mathrm{nm}) / \mathrm{Si}(1 \mathrm{~nm})$ by comparing the results for films B and C. In Fig. 7, the normalized integrated intensity for film $\mathrm{C}$ was as large as that of film B in conventional XPS. On the contrary, the intensity for film $\mathrm{C}$ was smaller than that of film B in total reflection XPS. This indicates that the "excessive diffusion of Si" was suppressed more effectively with the $\mathrm{Pd}(4 \mathrm{~nm}) / \mathrm{Si}(1 \mathrm{~nm})$ layer than with the $\mathrm{Pd}(5 \mathrm{~nm}) / \mathrm{Si}(5 \mathrm{~nm})$ layer, preventing the formation of the initial disordered layer.

In the $\mathrm{Pd} / \mathrm{Si}$ intermediate layer, the reduction of the thickness of $\mathrm{Si}$ under-intermediate layer is effective to suppress the formation of initial disordered layer, which is thought to improve the magnetic properties of $[\mathrm{Co} / \mathrm{Pd}]_{\mathrm{n}}$ film. On the contrary, when the $\mathrm{Si}$ layer was much thinner than the Pd layer, Si did not seem to form matrices at grain boundaries of Pd crystals, which hindered the physical separation of $[\mathrm{Co} / \mathrm{Pd}]_{\mathrm{n}}$ grains and thereby increased the intergranular exchange coupling of $[\mathrm{Co} / \mathrm{Pd}]_{\mathrm{n}}$ film. In this case, strong intergranular exchange coupling decreased $H_{\mathrm{c}}$ value and increased $\alpha$ value as shown in Figs. 1 (a) $\left(8<\delta_{\mathrm{Pd}}<10\right)$ and 1 (b) $\left(4<\delta_{\mathrm{Pd}}<5\right)$.

In summary, the Si under-intermediate layer should be sufficiently thin to suppress the formation of initial disordered layer, but it must be thick enough to form the matrices. It is concluded that a $\mathrm{Pd} / \mathrm{Si}$ intermediate layer with a thickness ratio of $\left(\delta_{\mathrm{Pd}} / \delta_{\mathrm{Pd} / \mathrm{Si}}, \delta_{\mathrm{Si}} / \delta_{\mathrm{Pd} / \mathrm{Si}}\right)=(0.7-0.8$, $0.2-0.3)$ meets both requirements.
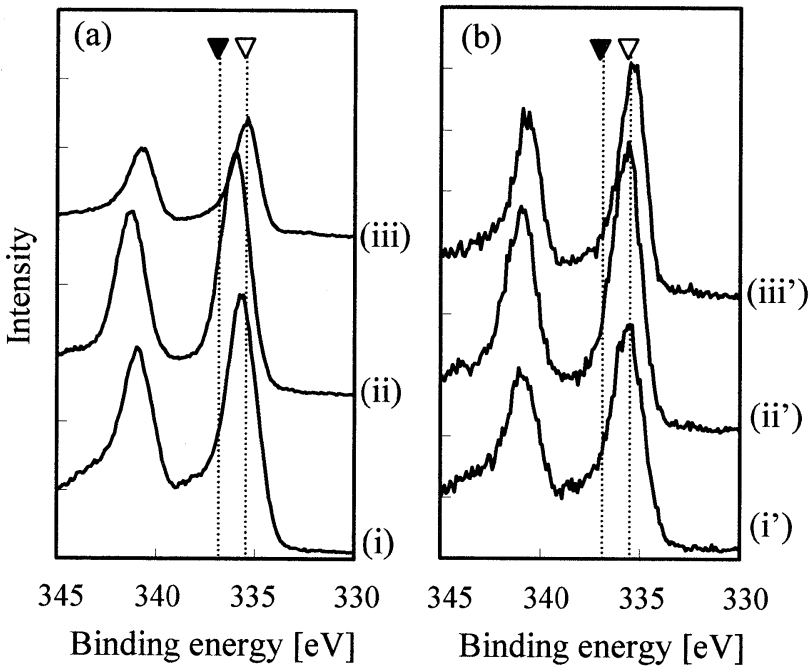

Fig.8 Pd-3d x-ray photoelectron spectra of $\mathrm{Pd} / \mathrm{Si}$ film on CoZrNb layer in the conventional (a) and total reflection (b) mode. Spectra labeled (i, i'), (ii, ii'), and (iii, iii') were obtained with films A, B, and $\mathrm{C}$, respectively. Open and solid triangles denote $\mathrm{Pd}-3 \mathrm{~d}_{5 / 2}$ binding energies of $\mathrm{Pd}$ and $\mathrm{Pd}_{2} \mathrm{Si}$, respectively. (Ref.22)

\section{Conclusion}

The thicknesses of Pd upper- and Si under-intermediate layers were optimized to develop $\mathrm{Co} / \mathrm{Pd}$ multilayer double-layered perpendicular recording media with the intermediate layer thinner than $10 \mathrm{~nm}$. Magnetic properties of the $\mathrm{Co} / \mathrm{Pd}$ multilayered media were found to be strongly dependent on the thickness ratios of $\mathrm{Pd}$ and $\mathrm{Si}$ to the total thickness of the $\mathrm{Pd} / \mathrm{Si}$ dual layer. When the thickness ratios $\left(\delta_{\mathrm{Pd}} / \delta_{\mathrm{Pd} / \mathrm{Si}}, \delta_{\mathrm{Si}} / \delta_{\mathrm{Pd} / \mathrm{Si}}\right)$ were in the range of $(0.7-0.8,0.2-0.3)$, high $H_{\mathrm{c}}$, small $\alpha$, and fine magnetic clusters were obtained. Conceivably, in the $\mathrm{Pd} / \mathrm{Si}$ layer with an optimized thickness ratio, $\mathrm{Pd}$ formed isolated grains, while Si served as matrices at the grain boundaries without diffusing excessively to the top surface of the $\mathrm{Pd} / \mathrm{Si}$ layer. The granular intermediate layer allowed to form the $\mathrm{Co} / \mathrm{Pd}$ multilayered film with well-defined grains, which hardly contained any initial microstructurally disordered region. The optimization of thickness ratios allowed the total thickness of $\mathrm{Pd} / \mathrm{Si}$ intermediate layer to be reduced successfully to as thin as $4 \mathrm{~nm}$ without deteriorating the magnetic properties of $\mathrm{Co} / \mathrm{Pd}$ multilayered media. The reduction of the $\mathrm{Pd} / \mathrm{Si}$ intermediate layer thickness led to the improvement of reproducing resolution, $\mathrm{D}_{50}$, and $\mathrm{S} / \mathrm{N}$ ratio. These results indicate that the use of an optimized $\mathrm{Pd} / \mathrm{Si}$ intermediate layer is highly effective for improving the $R / W$ performance of the $\mathrm{Co} / \mathrm{Pd}$ multilayered medium.

Acknowledgements This work was carried out at the "Center for Practical Nano-Chemistry" in the 21C-COE Programme, the Ministry of Education, Culture, Sports, 
Science and Technology, Japan (MEXT). The work was financially supported by a grant-in-aid of Special Coordination Funds for Promoting Science and Technology "Creation of Novel Magnetic Recording Materials Using Nano-Interface Technology" from MEXT, the Center of Excellence Research on "Establishment of Molecular Nano-Engineering by Utilizing Nanostructure Arrays and Its Development into Micro-Systems" from MEXT, and the Storage Research Consortium (SRC), Japan. The authors express their gratitude to Dr. S. Matsunuma, Hitachi Maxell, Ltd, Dr. G. Sáfrán, Hungarian Academy of Sciences, Mr. J. Ariake, and Dr. K. Ouchi, Akita Research Institute of Advanced Technology, for their valuable advice. The authors also express their gratitude to Mr. T. Goto, Waseda University, for his helpful collaboration in the XPS measurement, and to Dr. Y. Okinaka, Waseda University, for his assistance in preparing the manuscript.

\section{References}

1) P. F. Carcia, A .D. Meinhaldt, and A. Suna : Appl. Phys. Lett., 47, 178 (1985).

2) L. Wu, N. Honda, and K. Ouchi : IEEE Trans. Magn., 35, 2775 (1999).

3) W. Peng, O. Keitel, R. H. Victora, E. Koparal, J. H. Judy : IEEE Trans. Magn., 36, 2390 (2000).

4) J. Sayama, J. Kawaji, M. Tanaka, T. Asahi, S. Matsunuma, and T. Osaka : Trans. Magn. Soc. Jpn, 3, 8 (2003).

5) G.-L. Chen : J. Appl. Phys., 87, 6887 (2000).

6) H. Ohmori and A. Maesaka : J. Magn. Magn. Mat., 235, 45, (2001).

7) T. Shimatsu, M. Terakawa, I. Watanabe, H. Muraoka, and Y. Nakamura: IEEE Trans. Magn., 38, 2048 (2002).

8) W. Peng, W. Zhu, R. H. Victora, and J. H. Judy: J. Appl. Phys., 91, 8070 (2002).
9) S. Matsunuma, A. Yano, E. Fujita, T. Onuma, T. Takayama, and N. Ota : J. Appl. Phys., 91, 8073 (2002).

10) H. Domon, D. D. Djayaprawira, M. Takahashi, T. Endou, and S. Furukawa : J. Appl. Phys., 93, 8164 (2003).

11) H. Nakagawa, I. Takekuma, H. Nemoto, Y. Takahashi, Y. Hirayama, Y. Nishida, and Y. Hosoe : IEEE. Trans. Magn., 39, 2311 (2003).

12) J. Kawaji, T. Asahi, H. Hashimoto, T. Osaka, and K. Asami : Trans. Magn. Soc. Jpn, 3, 1 (2003).

13) J. Kawaji, T. Asahi, H. Hashimoto, J. Hokkyo, T. Osaka, S. Matsunuma, G. Sáfrán, J. Ariake, and K. Ouchi : J. Appl. Phys., 95, 8023 (2004).

14) L. Henke : Phys. Rev. A, 6, 94 (1972).

15) I. Tagawa, A. Takeo, and Y. Nakamura : J. Magn. Magn. Mat., 155, 341 (1996).

16) N. Honda, K. Ouchi, and S. Iwasaki : IEEE Trans. Magn, 38, 1615 (2002).

17) S. Chikazumi: Physics of Magnetism, p. 281 (John Wiley \& Sons, New York, 1964).

18) J. Hokkyo, T. Onoue, T. Asahi, K. Kuramochi, J. Kawaji, and T. Osaka : Digests of the 25th Annual Conference on Magnetics in Japan, Akita, Japan 2001, p. 5 (in Japanese).

19) J. Hokkyo, H. Hokkyo, H. Matsutera, K. Yamada, and T. Osaka: Digests of the 23rd Annual Conference on Magnetics in Japan, Kitakyushu, Japan 1999, p. 26, (in Japanese).

20) T. Onoue, T. Asahi, K. Kuramochi, J. Kawaji, T. Osaka, J. Ariake, K. Ouchi, G. Sáfrán, and N. Yaguchi : J. Appl. Phys., 92, 4545 (2002).

21) J. Kawaji, T. Asahi, T. Onoue, J. Sayama, J. Hokkyo, T. Osaka, and K. Ouchi : J. Magn. Magn. Mat., 251, 220 (2002).

22) P. J. Grunthaner, F. J. Grunthaner, A. Madhukar : J. Vac. Sci. Technol., 20, 680 (1982).

Received February 24, 2004; Accepted April 9, 2004. 